worthy observation was that three animals appeared to move with a somewhat shaking gait from eight to ten weeks after the commencement of the coffee feeding. When inspected by the veterinary officer he asked for close observations to be kept on them. However, this tendency decreased and was not noticeable after twelve weeks, when they moved about more or less normally.

During the last period the stock in both groups was mated and the coffee-feeding was terminated. The fertility of the two groups showed little difference in the proportion of fertile does from this batch of matings. In the control group eight produced litters and in the coffee ration seven, a difference of only one.

The diet had a direct effect upon thirst, and whereas the controls, receiving dry mash, drank $5 \cdot 2 \mathrm{oz}$. of water daily, those receiving a 10 per cent replacement of fresh (moist) coffee dregs only drank $3 \cdot 1 \mathrm{oz}$.

'Bruttini, A., "Uses of Waste Materials"' (1923).

${ }^{2}$ Aruch, E., L'Italia Agricola, 55, 299 (1918).

${ }^{3}$ Bretana, La Riforma Agraria, 1, 264 (1920).

\section{AIR-RAID DAMAGE AND ELECTRICITY SUPPLY}

\begin{abstract}
A
FURTHER series of articles in the February issues of the Electrical Review record instances of the air-raid damage sustained by overhead lines, cables, and substation equipment, and the steps taken to effect repairs and restore supply (see also Nature of February 7, p. 173). Although many engineers fully expected that overhead lines in the path of bomb blast would be levelled to the ground, actual damage has not reached a quarter of that anticipated. Admittedly, line conductors have suffered, and on pin type insulator lines, conductor binders have been severely strained, but it requires direct hits on towers or poles to interfere seriously with supplies. Bomb splinters, not blast, are generally responsible for the damage, stranded conductors showing definite evidence of having been severed. Wood poles appear to withstand blast better than steel ones, one large rural undertaking reporting that out of many near misses, only one wood pole was rendered unserviceable. Damage to pole transformers is rare and is usually only a slight puncturing of the casing.
\end{abstract}

As an indication of the amount of damage substation equipment can withstand, a switchboard which was blown right out by blast needed only minor wiring repairs. On another occasion a large outdoor transformer had its cooling tubes pierced at their lowest point by bomb splinters, and although the entire oil contents drained away the plant continued to function. At a certain static substation, a large bomb almost dived under the floor, which was split into four complete sections. Each of these, containing plant, was raised a foot and was at a different angle from its neighbour. The $6 \cdot 6-\mathrm{kv}$. switchgear was found at an angle of $15^{\circ}$ to the normal horizontal plane, many insulators were eracked and broken, all the trifurcating cable-box supporting lugs were torn away, and feeders were left hanging by their tails. The transformers were moved $2 \mathrm{ft}$. and lay taut on their cables, while the low-voltage floor-mounted switch-fuse gear was flat on its back with all the cable plumbing cracked. The roof was distributed among the plant, but the supply was maintained. A heavy bomb fell close to the side wall of another substation containing a $500-\mathrm{kw} ., 6 \cdot 6-\mathrm{kv}$. to $460-\mathrm{v}$. D.c. glass bulb rectifier equipment. The substation was rendered nearly roofless and quite windowless and doorless, but the electricity supply remained intact. When the internal debris was cleared away it was found that the entire substation equipment had been moved at least 6 in. One rectifier bulb was destroyed but it had successfully cleared its A.C. and D.C. protection; the remaining three bulbs were unharmed and complete automatic control remained.

A safeguard employed by one undertaking against incendiary bombs on slate-roofed buildings is the placing of iron sheeting above the $2 \mathrm{in}$. of sand which is recommended for covering the rafters or flooring immediately below the roof. This sheeting absorbs the impact of the bombs, which otherwise has a tendency to disturb the sand. Substations appear to suffer little damage from fire, and it is not uncommon to find that they are the only part surviving of buildings destroyed by this means.

Ideas are being rapidly revised on the subject of fire danger to transformers. Instances are recorded of their having been charred, their insulation burnt off underneath, their oil having been boiling and actually burning, and their connecting cables being burnt off to stumps at the point of entry, but in each of these cases the apparatus has been salvageable.

Damage to cables has provided the largest source of instructive facts and problems. Although, despite the most severe bending, stretching, twisting and flattening, cables frequently remain in service, it cannot be taken for granted that an apparently sound length is unharmed. In many cases steel armouring has been found to have saved cables from damage, but it is advisable to carry out a pressuretest from at least the draw boxes on either side of the crater. Sometimes damage is caused to cable joints by vibration from nearby bombs, resulting in water entry. Pilot cables are often damaged although the main cables remain unharmed. Remarkable instances are reported of cables remaining alive after almost unbelievable damage. A $6 \cdot 6 \cdot \mathrm{kv}$. cable cut by a bomb splinter remained in service for a fortnight, lying under debris without breaking down.

An indication of the depth of penetration that may be expected with some types of high-explosive bombs is provided by a chance hit on a $33 \cdot \mathrm{kv} ., 0 \cdot 18-\mathrm{sq}$. in. submarine cable passing across a river mouth. This was damaged although the cable was some feet below the river bed and the water was several feet deep.

Restoration of electricity supplies after an air raid is very much simplified by having the area split up into sections, which, in a large area, may be selfcontained and each have its own emergency repair gang. In repairing mains ruthless amputation of faulty sections is generally found to be the most successful course to adopt. Normally, cable saving has always been of paramount importance with dis. tribution engineers, but under 'bomb conditions' experience has shown the necessity for quickly 'cutting and sealing' at the most convenient place for, generally, the craters quickly fill with water from damaged mains. Comparatively seldom, however, does the urgency of restoring supplies justify tem. porary cable repairs. While special emergency joints utilizing cold-filling compound have apparently justified their makers' claims, the general consensus of opinion is that they are not often warranted on the score of saving a few extra hours and should be used only when immediate recommissioning of the 
cable is essential. It must be emphasized that while some manufacturers claim their cold-filling joints are permanent, these joints are primarily for emergency use, and permanent repairs usually have to be carried out later. Failure to appreciate the necessity for very efficient mixing was, in fact, the cause of the breakdown of an $11-\mathrm{kv}$. joint after three months' operation. Another undertaking has come to the conclusion that the use of these joints is advantageous for cables of $33-\mathrm{kv}$. and higher, considering the saving of approximately a day and a half in the repair work worth while. In the bridging of cables across craters, many devices have been widely adopted, such as the use of scaffold poles as supports and the suspension of the cables temporarily on adjacent walls. Another scheme is the utilization of steel structures to support the cables temporarily while other parties requiring access to the crater attend to their work. These steel structures, which are generally covered with boarding to give the cable protection against stray splinters of anti-aircraft shells, etc., are erected rapidly and leave an almost clear space around for other work to be undertaken.

Practically all undertakings have now come to the conclusion that there is nothing to be gained by attempting anything in the way of actual repairs, apart from isolating bad sections of the system and restoring supplies to sound sections by means of alternative switching, while the raid is still in progress, except in very special circumstances: Apart from the unwarranted risk to personnel, little can be done until daylight. Much time and money is spent unnecessarily on having emergency repair gangs on duty throughout the twenty-four hours, and without any question of slackness it has been proved in practice that a much more satisfactory arrangement is to have the men standing by in their own homes and to call them up by telephone, or even by messenger, only when actually needed.

\section{MARINE RESEARCH IN THE UNITED STATES}

$\mathrm{T}$ HE eight papers in the latest number of the Journal of Marine Research* deal with,all aspects of oceanography, physical, chemical, biological and bacteriological.

A. H. Woodcock continues an earlier inquiry into the effect of cold winds on a water surface. In shallow water the cooled surface water finds its way downwards by converging into small-scale streamings about $1 \mathrm{~cm}$. across and several centimetres apart running parallel downwind. In vertical section a shallow surface stratum is broken up into a series of convection cells, and at the surface there are alternate convergent and divergent strips. In the open sea the small-scale streaming is present on the surface of the large waves, but there is also a large-scale convection mechanism with streams 50-100 ft. apart. On the small scale, lycopodium powder dusted over the surface falls at once into the linear pattern, and the gathering of Sargassum weed into parallel strips under the influence of a cooling wind is used as evidence of large convection cells.

* Journal of Marine Research, Vol. 4, No. 2, 1941. Sears Foundation for Marine Research, Bingham Oceanographic Laboratory, Yale University
Whitney describes measurements of the scattering of daylight in sea water. Whatever the altitude of the sun the light becomes more and more vertical as it penetrates, until it appears to reach an equilibrium distribution in which the light received from below is about half that received horizontally and roughly a fortieth of that from above. The depth at which such equilibrium is reached seems to vary between 5 and 30 metres according to the turbidity of the water. The measurements were made off the United States Atlantic coast and in a freshwater lake.

The waters off the United States Pacific coast are described by R. B. Tibby, who has measured the proportions of subarctic and equatorial waters in a broad coastal belt.

The first of the chemical papers deals with the $\mathrm{Na} / \mathrm{Cl}^{\prime}$ ratio in sea water. The relative concentration of all important ions in the sea is remarkably constant, but Robinson and Knapman, using a direct analytical method, have found a slightly higher ratio of $\mathrm{Na}$. to $\mathrm{Cl}^{\prime}$ in the coastal waters of Puget Sound than in the open Pacific Ocean. The method will be of great value in studying small variations or continuous trends in the composition of sea water.

Sanderman and Utterback, measuring the radium content of bottom sediments off the west coast of America from Canada to the Arctic Ocean, confirm the earlier conclusion that deep sea sediments are richer in radium than those of the land areas, and that the concentration is largely confined to a very thin surface film. Their richest sample was one that was just skimmed from the sea bed, so fine that it took several days to settle. While admitting that the plankton is $100-1,000$ times as rich in radium as the surrounding water they agree with earlier workers that the role of plankton as a carrier of radium to the bottom is likely to be negligible; their sediments from the regions of most abundant plankton were no richer than those from the most barren areas.

The biological papers deal mainly with the phytoplankton. W. E. Allen discusses the mechanism by which diatoms suspend themselves at levels favourable for their growth, or in some way keep contact with them. He considers their production of oils and gases, methods by which they can exert more or less friction on the surrounding water, and the possible effects of turbulent water movements. He believes that there are no reliable data for estimating the rate of sinking, laboratory methods lacking dependability for estimating the rates under complex sea conditions.

Gordon A. Riley summarizes his work on the plankton of the western North Atlantic in a diagram which illustrates the relationships between the phytoplankton and its environment. He makes an attempt to give algebraic expressions for the relative importance of the different factors. The equations. need testing, and are likely to apply better to average than particular conditions, but they give some hope that the phytoplankton production will eventually be predictable with some accuracy.

A bacteriological paper is by C. W. Hock, who has isolated bacteria capable of decomposing chitin, the tough leathery substance found in both rigid and flexible parts of most invertebrates. The bacteria which attack this very inactive substance have been found in sea water, marine sands and muds, and in the intestines of several marine animals. Two species are described, both aerobic ; ammonia-reducing substances and organic acids were among the products of decomposition.
G. E. R. DEACoN. 